\title{
Letters to the
}

\section{Editor}

\section{Pathology of fresh versus cryopreserved homograft heart valves}

\section{To the Editor:}

In "The Pathology of Fresh and Cryopreserved Homograft Heart Valves: An Analysis of Forty Explanted Homograft Valves," Koolbergen and colleagues ${ }^{1}$ attempted nicely to reconstruct the sequence of events leading to failure of homografts from a data set of 40 explanted valves examined histologically. Despite the limitations of such a study and the significant variability among patients, they convincingly observed a reduction in valve leaflet cellularity that appears to occur within the first year after implantation.

The loss of cellular elements has also been previously reported by others, but what remains unclear is the exact cause for this loss of donor cells. ${ }^{2,3}$ Although it is clear is that some immune cell infiltration can be demonstrated, as well as evidence of donor-specific immune activation, a direct causal relationship remains difficult to prove. In this article Koolbergen and colleagues ${ }^{1}$ described some early infiltration of immune effector cells, such as macrophages and $\mathrm{T}$ lymphocytes. This observation may in fact represent evidence of immune-related valve injury, despite the absence of up-regulation of cell adhesion molecules, because the timing for up-regulation of cell adhesion molecules may be quite difficult to detect and impossible to evaluate with certainty in this type of analysis.

What is particularly interesting about this loss of cellular elements is that similar findings have been duplicated in a rat model of allograft failure, in which valve leaflet cellularity was demonstrated to be significantly reduced with time. ${ }^{4}$ In this rat model immune-specific cells (T lymphocytes) were recruited in allografts, resulting in apoptotic cell death of donor cellular elements. ${ }^{4}$ The entire process was absent in syngeneic valves and could be inhibited by T-cell immunosuppression and cell adhesion molecule block- ade, suggesting that allograft valve failure is at least in part immune mediated. ${ }^{4,5}$ Most of the evidence for immune-mediated damage in this model occurred in the first 2 weeks after implantation, and by 4 weeks the valves were largely acellular. It is not surprising then that Koolbergen and colleagues ${ }^{1}$ could find little evidence of immune-mediated injury-despite showing, in the valve explanted at 2 weeks, an obvious T-cell infiltrate. Any such injury almost certainly had to have occurred before the majority of these valves were explanted (median 4 years).

The contribution of cellular elements to the homograft survival appears poor, as suggested by their significant disappearance early after implantation. Taken together, a homograft with less viable cellular elements and well-preserved ultrastructure may be ideal in provoking the least donor-specific immune response and therefore contributing to limited valve injury after implantation. This finding supports current efforts to create a cell-free or nonimmunogenic homograft for clinical use. $^{6}$

Jean Francois Légaré, MD Dalhousie University Halifax, Nova Scotia, Canada David B. Ross, $M D$ University of Alberta Edmonton, Alberta, Canada

\section{References}

1. Koolbergen DR, Hazekamp MG, de Heer E, Bruggemans EF, Huysmans HA, Dion RA, et al. The pathology of fresh and cryopreserved homograft heart valves: An analysis of forty explanted homograft valves. J Thorac Cardiovasc Surg. 2002;124:689-97.

2. Mitchell RN, Jonas RA, Schoen FJ. Pathology of explanted cryopreserved allograft heart valves: comparison with aortic valves from orthotopic heart transplants. J Thorac Cardiovasc Surg. 1998;115:118-28.

3. Mitchell RN, Jonas RA, Schoen FJ. Structure-function correlations in cryopreserved allograft cardiac valves. Ann Thorac Surg. 1995;60(2 Suppl):S108-13. 
4. Légaré JF, Ross DB, Issekutz TB, Ruigrok W, Creaser K, Hirsch GM, et al. Prevention of allograft heart valve failure in a rat model. J Thorac Cardiovasc Surg. 2001; 122:310-7.

5. Légaré JF, Lee TD, Creaser K, Ross DB. T lymphocytes mediate leaflet destruction and allograft aortic valve failure in rats. Ann Thorac Surg. 2000;70:1238-45.

6. Cebotari S, Mertsching H, Kallenbach K, Kostin S, Repin O, Batrinac A, et al. Construction of autologous human heart valves based on an acellular allograft matrix. Circulation. 2002;106(12 Suppl 1):I63-8.

doi:10.1016/S0022-5223(03)00597-X

\section{Obstruction of St Jude Medical valves in the aortic position}

\section{To the Editor:}

I enjoyed the recent article by Teshima and coworkers, "Obstruction of St Jude Medical Valves in the Aortic Position: Histology and Immunohistochemistry of Pannus" (J Thorac Cardiovasc Surg. 2003;126:401-

$7)$. I recently reoperated on 2 young female patients with dysfunction of St Jude Medical prosthetic valves (St Jude Medical, Inc, St Paul, Minn) in the aortic position. Both patients had moderate amounts of pannus formation on the valve. Both patients had significant periods during their postoperative management when anticoagulation was discontinued or inadequate. Perhaps more significantly, they had small aortic roots. The explanted St Jude Medical valves were $19 \mathrm{~mm}$ in both patients.

Are young female patients who receive 19- or 21-mm implants for small aortic roots predisposed toward pannus formation? Is pannus formation detected only in 19- and 21-mm valves, in which a minor reduction in orifice area may result in clinically apparent hemodynamic deterioration? I noticed the female predilection in the published series and wondered about the size of the explanted prostheses and if the postimplantation coagulation history of these patients was known.

Frank A. Baciewicz, Jr, MD Department of Cardiothoracic Surgery Harper Hospital

Wayne State University

Detroit, MI 48201

doi:10.1016/j.jtcvs.2003.11.066

\section{Reply to the Editor:}

We read with interest the letter by Dr Baciewicz regarding his experience of two young female patients with prosthetic valve dysfunction as a result of pannus formation. In our study, we showed histologic and immunohistochemical findings of pannus tissue that caused prosthetic valve dysfunction after aortic valve replacement. We believe that our study provides information useful to elucidate the mechanisms of pannus formation in patients receiving prosthetic valves. We also think, however, that our findings are not sufficient to reach conclusion regarding the complete pathogenetic mechanisms of this disorder, and further prospective studies including more patients and control specimens are required.

The sizes of the prosthesis explanted in this study were $21 \mathrm{~mm}$ in 6 patients (all female), $23 \mathrm{~mm}$ in 2 ( 1 male and 1 female), $25 \mathrm{~mm}$ in 1 (male), and $27 \mathrm{~mm}$ in 1 (male). The ratio of effective orifice area (according to the manufacturer's report) to body surface area, as an index of patient-prosthesis mismatch, in our patients with pannus receiving $21-\mathrm{mm}$ prostheses was $1.0 \pm$ $0.1 \mathrm{~cm}^{2}$. The ratio was slightly lower than that in patients with normally functioning 21-mm aortic prostheses $\left(1.2 \pm 0.2 \mathrm{~cm}^{2}\right){ }^{1}$ Because remaining significant transvalvular gradient after valve replacement may induce shear stress at the periannular tissue, patient-prosthesis mismatch per se can be a cause of excessive intimal growth. Another important issue in patients with small aortic annuli is mechanical contact between the ventricular septum and the pivot guard of the prosthesis. It is conceivable that the pivot guard protrudes to the left ventricular side, which is unique to the design of St Jude Medical valves, ${ }^{2}$ and thus is readily in contact with the hypertrophied ventricular septum. Recently, we carefully examined patients with prosthetic valve dysfunction in the aortic position with multidetector row computed tomography. ${ }^{3}$ In that study, these pathognomic conditions and pannus formation located mainly on the pivot guard of the septal side were confirmed. Therefore the possibility exists that patients with small aortic annuli are predisposed toward pannus formation regardless of the absence of patient-prosthesis mismatch, especially when the patient has a small left ventricular outflow tract.

During the period of this study, 615 patients underwent aortic valve replacement with St Jude Medical valves, and 265 of those were female (43\%). Therefore, as indicated by Dr Baciewicz, the female proportion of patients who had prosthetic valve dysfunction develop tended to be higher than that of patients with normal prosthetic valve function. A major reason for this appears to be simply that female patients had smaller aortic annulus diameters. The mean age of our 7 female patients who developed pannus formation was 62.6 \pm 6.7 years, which did not differ from our 265 female patients with normally functioning aortic valve prostheses. Although the number of patients is small and our results do not have statistical power, patient age per se may not be an important factor in pannus formation.

In our study, 4 of 11 patients with prosthetic valve dysfunction had a short-term history of warfarin withdrawal during treatments for noncardiac disease (abdominal operations and dental treatment). The remaining 7 patients received adequate anticoagulation therapy with warfarin throughout the postoperative period. The observations during reoperations and histologic examinations of periannular tissue did not demonstrate thrombus in all patients. These findings, however, do not negate the presence of perivalvular thrombus at an earlier period of prosthetic valve dysfunction. Because pannus can develop as a result of prosthetic valve thrombosis, inadequate anticoagulation also is considered to be a risk factor for this disorder.

The cause of prosthetic valve dysfunction related to pannus may be multifactorial, and definitive mechanisms for this disorder have not yet been conclusively shown. On the basis of our findings that excessive expression of transforming growth factor $\beta$ was observed in the pannus, however, chronic inflammatory reaction in the periannular lesions-perhaps as a result of surgical trauma, reaction to the foreign materials, mechanical contact, inadequate anticoagulation, and shear stress at the annulus-may be associated with pannus formation.

Hideki Teshima, MD Nobuhiko Hayashida, MD Shigeaki Aoyagi, MD

Department of Surgery Kurume University 67 Asahi-machi Kurume, Japan 